\title{
Pembuatan Alat Pencuci Kaki Otomatis Berbasis Mikrokontroler AtMega16
}

\author{
Hanggoro Aji Al Kautsar ${ }^{1}$, Sujiliani Heristian ${ }^{2}$, Rachmat Adi Purnama ${ }^{3}$,Agus Tri Purnomo ${ }^{4}$, Ehon \\ Abdulmanan 5
}

\author{
${ }^{1}$ Universitas Bina Sarana Informatika \\ hanggoro.hgr@bsi.ac.id \\ ${ }^{2}$ STMIK Nusa Mandiri \\ sujilianiheristian30@gmail.com \\ ${ }^{3}$ Universitas Bina Sarana Informatika \\ rachmat.rap@bsi.ac.id \\ ${ }^{4}$ Universitas Bina Sarana Informatika \\ agustripurnomo@gmail.com \\ ${ }^{5}$ Universitas Bina Sarana Informatika \\ ehonabdulmanan@gmail.com
}

Cara Sitasi: Al Kautsar, H. A., Heristian, S., Purnama, R. A., Purnomo, A. T., \& Abdulmanan, E. (2019). Pembuatan Alat Pencuci Kaki Otomatis Berbasis Mikrokontroler AtMega 16. Jurnal Teknik Komputer AMIK BSI, 1-6.

\begin{abstract}
Prayer is an obligation that must not be abandoned except because of aging or obstruction that is justified by religious law, such as; women who have menstruation or postpartum. The person who leaves the prayer without a reason that is justified in the shari'ah of the law is an infidel. One of the conditions of prayer is in a holy and clean condition, but researchers can see the condition of a prayer house or mosque, the condition of the lower floor is dirty because many people pass by stepping on the floor of the lower terrace with the condition of using shoes. There is also a new one from the bathroom with no feet who then stepped on the floor. Stepping on a dirty floor will cause doubts. To cancel these doubts, it is better for researchers to maintain proper ablution conditions. Therefore, researchers made Automatic Foot Washers with Pear Sensors Based on Atmega Microcontroller 16. PIR (Pasive Infra Read) is one tool that can be used as a sensor to detect human presence which is then developed into an automatic footwashing device. And with the addition of an automatic door, the pilgrims will be orderly to wash their feet before entering the mosque. As well as the drying fan that the researcher added after the doorstop will make the pilgrim's feet dry immediately before stepping on the prayer area at the mosque.
\end{abstract}

Keywords: Mikrokontroler, AtMega16, Sensor PIR

\section{PENDAHULUAN}

Shalat merupakan salah satu kewajiban umat Islam, seperti yang di jelaskan dalam ayat Al-Quran "...maka dirikanlah salat, sesungguhnya shalat adalah kewajiban yang ditetapkan waktunya bagi orang-orang beriman". [Surat An-Nisa ayat 103] . Shalat merupakan tiang agama dan amalan yang pertama dihisab pada hari kiamat. Kalau salatnya baik maka baik semua amalan lainnya dan kalau salatnya rusak maka rusak semua amalannya. Shalat merupakan kewajiban yang tidak boleh ditinggalkan kecuali karena uzur atau halangan yang dibenarkan oleh syariat agama, seperti; wanita-wanita yang haid atau nifas. Orang yang meninggalkan shalat tanpa alasan yang dibenarkan syariat hukumnya adalah kafir.

Salah satu syarat sholat adalah dalam kondisi suci dan bersih, namun peneliti dapat melihat kondisi tempat ibadah mushola atau masjid kondisi lantai bawah dalam keadaan kotor karena banyak masyarakat yang lalu lalang menginjak lantai teras bawah dengan kondisi menggunakan sepatu. Ada juga yang baru dari kamar mandi dengan tidak beralas kaki yang kemudian menginjak lantai tersebut.

Menginjak lantai yang kotor akan menimbulkan keraguan. Untuk membatalkan keraguan tersebut lebih baik peneliti tetap menajaga kondisi wudhu pada semestinya. Oleh sebab itu peneliti membuat 
Alat Pencuci Kaki Otomatis Dengan Sensor Pir Berbasis Mikrokontroler Atmega 16. Hal ini akan jauh lebih hemat daripada peneliti memindahkan tempat wudhu ke tempat lain.

\section{KAJIAN LITERATUR}

Dalam pembuatan Alat Pencuci Kaki Otomatis Dengan Sensor Pir Berbasis Mikrokontroler Atmega 16 menggunakan komponen aktif dan komponen pasif. Adapun komponen yang digunakan antara lain IC Atmega 16, Transformator , LED, Transistor, Sensor Pir, Motor DC, Resistor, Diode, Kapasitor, IC Regulator 7805 dan lain-lain.

Untuk mendukung pembuatan alat maka perlu adanya penjelasan tentang komponen elektronika yang peneliti gunakan. Komponen elektronika tersebut terdiri dari komponen pasif dan komponen aktif.

1. Komponen aktif dan pasif

Komponen pasif merupakan komponen yang menerima daya atau energy seperti resistor, kapasitor dan transformator sedangkan komponen aktif terdiri dari dioda, transistor dan ic (Prihono, 2010).

2. Mikrokontroler AtMega16

Mikrotontroler merupakan sebuah computer atau pengendali mikro atau sebuah computer kecil didalam sebuah IC/chip. Dalam sebuah IC/chip mikrokontroler terdapat CPU, memori, timer, saluran komunikasi serial dan paralel, port input/output, ADC dan lain-lain. Dan AVR adalah mikrokontroler RISC (Reduce Intruction Set Computer) 8 bit berdasarkan arsitektur Hervard yang dibuat oleh Atmel pada tahun 1996." Secara umum mikrokontroler AVR dapat dikelompokan menjadi 5 kelompok, yaitu ATini, AT90Sxx, ATMega, AVRXMega, dan AVR32 UC3. Mikrokontroler ATMEGA 16 merupakan salah satu jenis AVR dengan kemasan 40 pin (Sasongko, 2012).

3. IC 7805

Merupakan komponen elektronika yang berfungsi menstabilkan tegangan sebesar 5 volt dan dengan adanya IC ini keluaran tegangan akan didtabilkan menjadi DC murni sebesar 5V(Wibawanto, 2008).

4. Relay

Relay bisa dikendalikan secara elektronik dan juga relay bisa digunakan sebagai saklar dengan arus besar tapi dikendalikan dengan tegangan dan arus rendah (Suyadhi, 2011).

5. Sensor PIR (Passive Infrared Receiver)

Sebuah sensor berbasiskan infrared. PIR tidak memancarkan apapun seperti IR LED. Sesuai dengan namanya 'passive', sensor ini hanya merespon energi dari pancaran sinar inframerah pasif yang dimiliki oleh setiap benda yang terdeteksi olehnya (Mikrokontroler, Dan, \& Time, 2013). Dengan pemasangan sensor PIR ini maka apabila ada pergerakan manusia yang melewati sensor PIR, maka sensor akan mendeteksi keberadaan manusia (Ratnadewi, Agus Prijono, 2015).

\section{METODOLOGI PENELITIAN}

Adapun metode penelitian yang kami gunakan dalam pencarian dan pengumpulan data serta informasiinformasi yang mendukung di dalam pembuatan penelitian ini adalah sebagai berikut :

1. Pengamatan (observation)

Penelitian ini melakukan pengamatan secara langsung segala sesuatu yang berkaitan dengan objek penelitian. Peneliti menggunakan teknik observasi di dalam pengumpulan data yaitu agar dapat melihat proses atau prosedur kerja secara langsung dan juga untuk dapat mengetahui secara pasti segala sesuatu yang diperlukan pada saat terjadinya proses.

2. Wawancara (Interview)

Tujuan peneliti menggunakan teknik wawancara adalah untuk mencari dan memeriksa kebenaran suatu informasi juga mendapatkan informasi yang spesifik dan jelas dari pihak pengelola atau pengurus mushola atau masjid.

3. Studi Pustaka (library Study)

Sebagai pendukung untuk mencari berbagai informasi atau literature peneliti menggunakan teknik studi pustaka dengan mengambil beberapa literatur berupa buku, referensi, jurnal dan catatan-catatan yang berkaitan dengan penelitian ini.

\section{HASIL DAN PEMBAHASAN}

Alat Pencuci Kaki Otomatis Dengan Sensor PIR Berbasis Mikrokontroler Atmega 16 merupakan sebuah perancangan alat yang di harapkan menjadi solusi untuk menjaga kesucian dan kebersihan masjid yang di jadikan sebagi tempat ibadah untuk umat muslim.

Alat ini menggunakan dua sensor PIR. Sensor pertama peneliti pasang di teras masjid, dimana teras masjid tersebut adalah salah satu lokasi yang selalu di lewati jamaah baik yang baru datang atau yang baru keluar dari area wudhu . Ketika jamaah berada di tempat pencuci kaki maka sensor PIR mendeteksi bahwa ada jamaah yang ingin mencuci kaki. Ketika sensor mendeteksi jamaah, maka akan memberi perintah pada pompa air. Pompa air yang menyala akan mengalirkan air menuju kaki jamaah yang ingin masuk ruang masjid. Dalam hitungan 10 detik secara otomatis pintu menuju ruangan masjid akan terbuka dan jamaah bisa masuk kedalam masjid. Sensor PIR yang kedua peneliti letakan sesudah palang pintu. Sensor yang kedua ini berfungsi untuk menutup pintu dan menyalakan kipas yang berfungsi untuk mengeringkan kaki jamaah sehingga kaki jamaah 
yang basah akan langsung kering. Dengan demikian diharapkan ruangan masjid atau area sholat akan selalu dalam kondisi bersih dan suci, jamaah akan khusuk dalam sholat.

1. Blok Diagram Alat

Untuk menggambarkan keseluruhan alat maka perlu dibuat blok diagram. Blog diagram tersebut menggambarkan alat yang penulis buat. Blok diagram alat yang penulis buat bisa dilihat pada gambar di bawah ini.

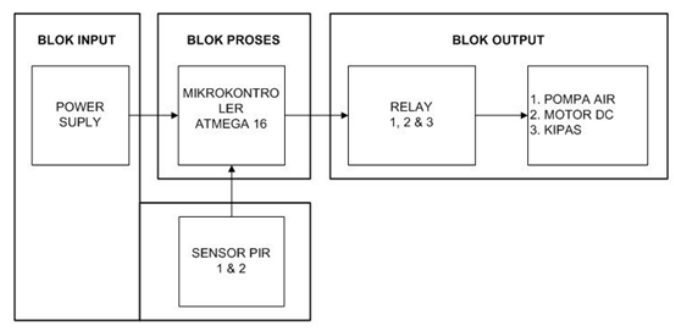

Sumber: Hasil Penelitian (2019)

Gambar 1 : Blok Diagram Alat

Dan juga pada rangkaian berikut ini

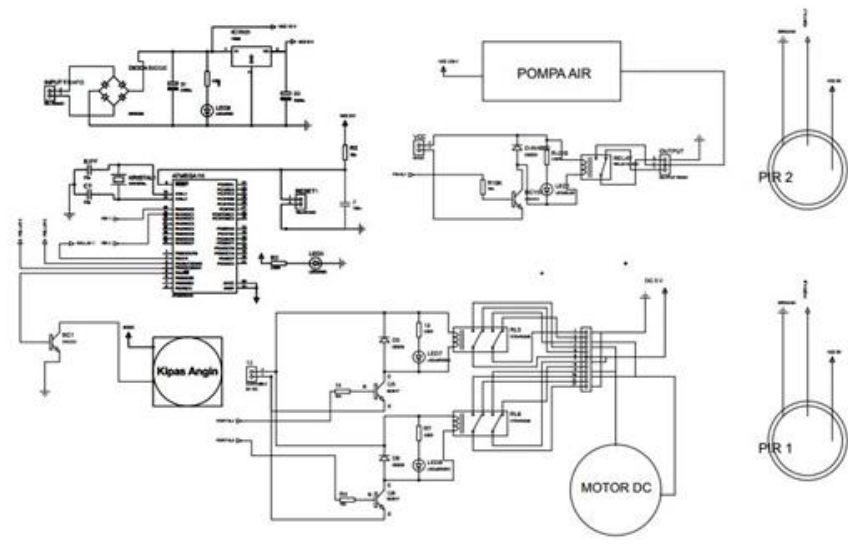

Sumber: Hasil Penelitian (2019)

Gambar 2. Rangkaian Alat

Secara umum mikrokontroler yang penulis gunakan untuk menjalankan Alat Pencuci Kaki Otomatis ini menerima sebuah inputan dari dua buah sensor PIR yang mendeteksi adanya manusia atau jamaah yang akan masuk kedalam masjid, sensor pertama akan membuat sebuah output kepada pompa dorong yang menyemprotkan air ke kaki jamaah, kemudian dilanjutkan ke motor DC yang membuka pintu masjid. Setelah jamaah masuk melewati pintu masjid, sensor kedua akan berkerja dan membuat sebuah output ke motor DC untuk menutup pintu dan menyalakan kipas yang di letakan di tangga menuju area sholat, kipas angin ini berfungsi untuk mengeringkan kaki jamaah yang sudah tercuci kakinya.

\section{Rangkaian Catu Daya}

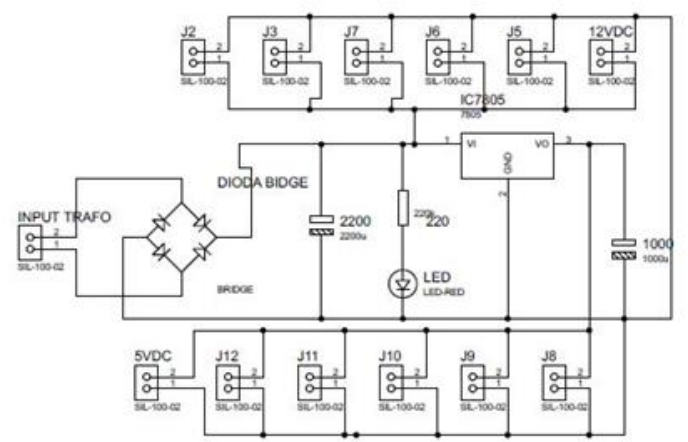

Sumber: Hasil Penelitian (2019)

Gambar 3. Rangkaian Catu Daya

Pengujian terhadap rangkaian catu daya dimaksudkan untuk mengetahui dan memastikan tegangan keluaran catu daya yang akan digunakan untuk memacu alat pendeteksi kebocoran gas, sistem minimum mikrokontroler, dan sistem output.

Hasil pengukuran terhadap rangkaian catu daya adalah sebagai berikut:

a. Tegangan sumber dari PLN :220 V (ac)

b. Tegangan sekunder trafo $\quad: 11,5 \mathrm{~V}$ (ac)

c. Tegangan keluaran penyearah $: 9,5 \mathrm{~V}$ (ac)

Hal tersebut telah sesuai / memenuhi kriteria catu daya yang diperlukan untuk alat ini.

2. Sensor PIR (Passive Infrared Receiver)

Sensor PIR memiliki fungsi sebagai modul untuk pemberian input data, data dari sensor ini berupa arus listrik. Disaat sensor tidak mendeteksi gerakan manusia maka ia memiliki output 0,5 VDC atau berlogika 0 (nol), dan apabila ia mendeteksi gerakan manusia maka arus input akan naik menjadi 5 VDC atau berlogika 1 (satu). Dalam alat yang penulis buat, penulis menggunakan dua buah sensor PIR yang memiliki fungsi berbeda-beda. Untuk lebih jelasnya akan penulis uraikan dari gambar di bawah ini. 




Sumber: Hasil Penelitian (2019)

Gambar 4. Rangkaian Sensor PIR 1

Sensor PIR 1 berfungsi untuk menyalakan pompa air dan membuka pintu. Jika sensor PIR ini mendeteksi gerakan manusia, maka sensor PIR tersebut akan memberikan inputan kepada mikrokontroler yang selanjutnya akan dilanjutkan ke proses output.

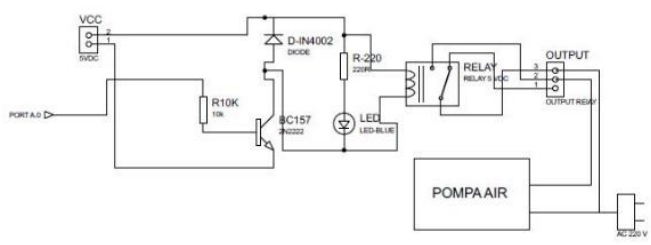

Sumber: Hasil Penelitian (2019)

Gambar 6. Rangkaian Pompa Air

Dalam perancangan alat penulis pompa air berfungsi untuk mengalirkan air dari bak penampung menuju area cuci kaki. Jenis pompa air yang penulis gunakan memerlukan tegangan AC $220 \mathrm{~V}$, sehingga untuk menjalankan pompa air ini penulis menggunakan relay sebagai saklar untuk menghidupkan pompa air. Relay bekerja ketika mendapat logika 1 (satu) dari PORT A.0. Sehingga jika relay mendapatkan inputan dari mikrokontroler maka pompa air akan jalan.

\section{Kipas Angin}

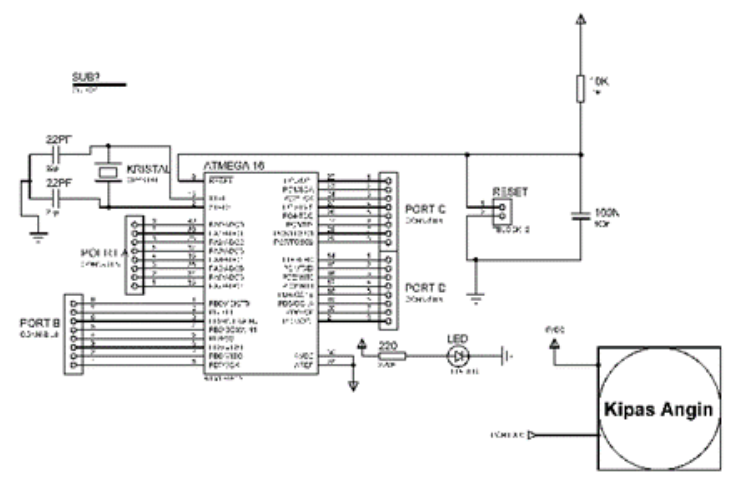

Sumber: Hasil Penelitian (2019)

Gambar 7. Rangkaian Kipas Angin

Jenis kipas angin yang kita gunakan adalah jenis kipas angin DC yang memerlukan catu daya sebesar 5V. Kipas angin ini bekerja ketika mendapatkan logika 1 (satu) dari PORT B.4. Fungsi dari kipas angin yang kita gunakana adalah untuk mengeringkan kaki jamaah.

4. Sistem Minimum

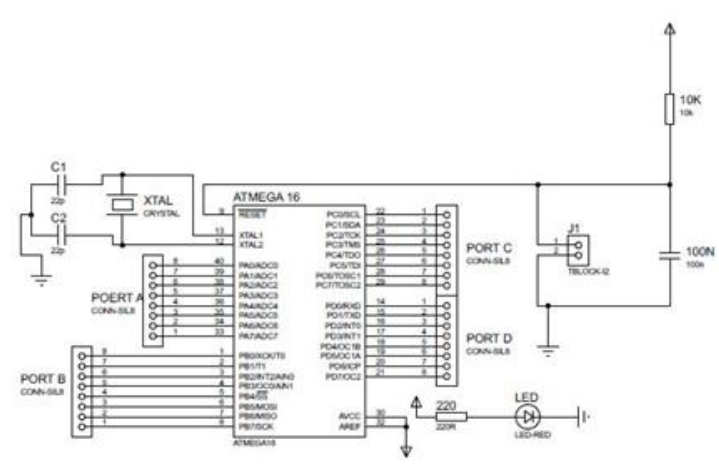

Sumber: Hasil Penelitian (2019)

Gambar 8. Sistem Minimum

Rangkaian sistem minimum (sismin) ini terdiri dari beberapa komponen pendukung seperti Kristal, kapasitor elco, kapasitor keramik, resistor dan push button. Komponen-komponen pendukung tersebut memiliki fungsi masingmasing yang berbeda. Kristal memiliki fungsi mengaktifkan gelombang pulsa yang terdapat pada IC Atmega16 dan didukung oleh kapasitor keramik pada kaki Kristal.

Push button berfungsi untuk mereset program yang ada pada IC Atmega16 agar kembali kepada program awal, sedangkan kapasitor elco berfungsi menyaring noise saat push button ditekan. Untuk pengoperasian sistem minimum maka ia membutuhkan tegangan +5 Volt yang ia dapatkan dari catu daya. Seluruh proses akan berlangsung pada sistem minimum Atmega16 dan dari hasil proses akan dikirim ke output.

\section{Perancangan Program}

Alat pencuci kaki otomatis dengan sensor PIR yang penulis buat menggunakan miktokontroler Atmega 16. Mikrokontroler Atmega 16 memerlukan program untuk menjalankan intruksi-intruksi hardware sesuai dengan konsep alat. Dalam pembuatan ini menggunakan menggunakan pemrograman avr atmega16 (Andrianto, 2015)(Sasongko, 2012). Pada pembahan ini penulis akan jelaskan mengenai 
flowchart program dan kontruksi sistem (Coding).

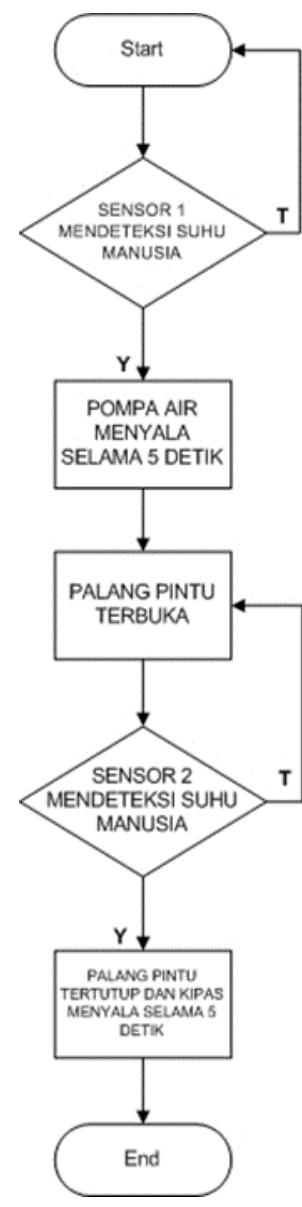

Sumber: Hasil Penelitian (2019)

Gambar 9. Flowchart

\#include <mega16.h> // mendeklarasikan penggunaan IC ATmega16 dengan semua librarynya

\#include <delay.h> // mendaklarasikan penggunaan perintah delay void main(void)

\{

//setting awal port A pada kaki 33 s/d 40

PORTA=0xFF; // PORT A dikasih awalan 1

DDRA $=0 \times 00 ; \quad / /$ PORT A dijadikan input

//setting awal port B pada kaki 1 s/d 8

PORTB $=0 x 00 ; / /$ port $\mathrm{B}$ dikasih awalan 0

$\mathrm{DDRB}=0 \mathrm{xFF}$; // PORT B dijadikan output

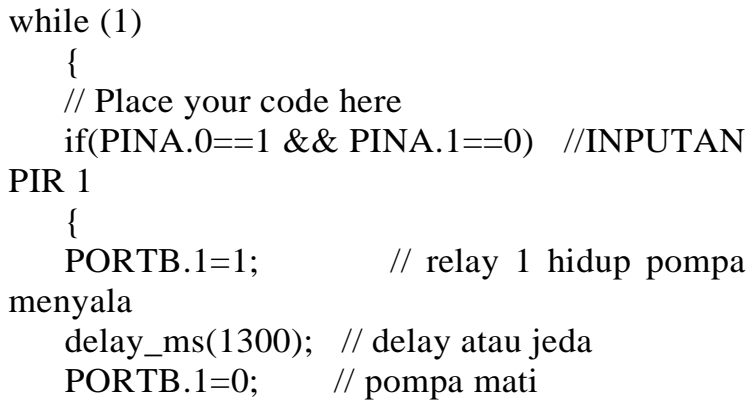

delay_ms(50); // delay atau jeda

PORTB. $2=1 ; \quad / /$ relay 2 . A menyala $>$ motor

DC berputar $\mathrm{CCW}>$ pintu terbuka

PORTB.4=1; // kipas berputar

delay_ms(150); // delay atau jeda

PORTB. $2=0 ; \quad / / / /$ relay $2 . \mathrm{A}$ mati $>$ motor

DC berhenti

delay_ms(1000); // delay atau jeda

PORTB.4=0; // kipas mati

\}

if(PINA. $1==1 \& \&$ PINA. $0==0) \quad / /$ INPUTAN

PIR 2

\{

PORTB. $3=1 ; \quad / /$ relay $2 . \mathrm{B}$ menyala $>$ motor

DC berputar $\mathrm{CW}>$ pintu tertutup

delay_ms(150); // delay atau jeda

PORTB. $3=0 ; \quad / /$ relay $2 . \mathrm{B}$ mati $>$ motor $\mathrm{DC}$ berhenti

\}
\}

Pada alat ini, Mikrokontroler ATMEGA 16 digunakan sebagai pusat kendali atau kontrol keseluruhan sistem meliputi Menyalakan pompa air, menyalakan Motor DC dan menyalakan kipas angin. Saat sensor 1 mendeteksi jamaah akan memberikan sebuah input perintah kepada Mikrokontroler untuk menyalakan pompa air. Setelah delay selama 5 detik maka Mikrokontroler akan memberikan perintah yang ke dua untuk menyalakan Motor DC sebagai penggerak pintu masuk masjid.

\section{KESIMPULAN}

Dari hasil perancangan pembuatan dan pengujian alat pencuci kaki otomatis dengan sensor PIR yang peneliti buat dapat disimpulkan bahwa PIR (Pasive Infra Read) merupakan salah satu alat yang dapat di gunakan sebagai sensor pendeteksi keberadaan manusia yang kemudian di kembangakan menjadi alat pencuci kaki otomatis. Dan dengan adanya tambahan pintu otomatis akan membuat jamaah menjadi tertib untuk cuci kaki sebelum masuk ke mushola. Serta kipas pengering yang peneliti tambahkan sesudah palang pintu akan membuat kaki jamaah langsung kering sebelum menginjak area sholat di mushola.

\section{REFERENSI}

Andrianto, H. (2015). Pemrograman Mikrokontroler AVR ATmegal6 Menggunakan Bahasa C (CodeVisionAVR) revisi kedua. Bandung: Informatika Bandung. 
Mikrokontroler, B., Dan, A., \& Time, R. (2013). VOL . 6 NO . 1 Maret 2013, 6(1), 146-162.

Prihono. (2010). Jago Elektronika. Jakarta: Kawan Pustaka.

Ratnadewi, Agus Prijono, Y. S. (2015). Dasar-dasar Rangkaian Listrik. Bandung: Alfabeta.

Sasongko, B. H. (2012). Pemrograman Mikrokontroler dengan bahasa C. Yogyakarta: Andi.

Suyadhi, T. D. S. (2011). Buku Pintar Robotika (I, 1st Pub). Yogyakarta: Andi.

Wibawanto, H. (2008). Elektronika Dasar: Pengenalan Praktis. Jakarta: Elex Media Komputindo.

\section{PROFIL PENULIS}

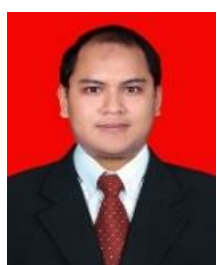

Hanggoro Aji Al Kautsar - Lahir di Jakarta, 23 Januari 1990, merupakan dosen pada institusi AMIK BSI Tangerang dengan latar belakang pendidikan ilmu komputer pascasarjana STMIK Nusa Mandiri Jakarta.

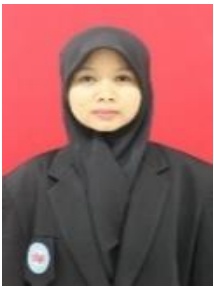

Sujiliani Heristian, S.Kom - Lahir di Tangerang, 30 Oktober 1995. Strata 1 Pada Tahun 2017 Program Studi Teknik Informatika STMIK Nusa Mandiri dan sedang menempuh S2 jurusan Ilmu Komputer di STMIK Nusa Mandiri.

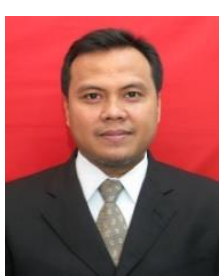

Rachmat Adi Purnama M.Kom. Jakarta 26 Nopermber 1970, Tahun 1997 lulus dari Program Strata Satu (S1) Jurusan Sistem Informasi STMIK BUDI LUHUR Jakarta. Tahun 2010 lulus dari Program Strata Dua (S2) Jurusan Magister Ilmu Komputer STMIK Nusa Mandiri Jakarta. Tahun 2011 sudah tersertifikasi dosen dengan Jabatan Fungsional Akademik Lektor di AMIK BSI Jakarta..

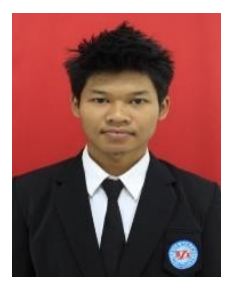

Agus Tri Purnomo - Lahir di Ponorogo, 20 januari 1995, D3 Teknik computer di AMIK BSI Jakarta.

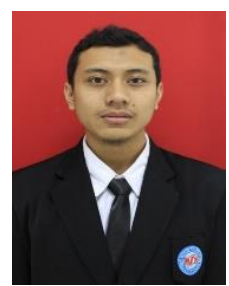

Ehon Abdulmanan - Lahir di Kuningan, 19 April 1994, D3 pada tahun 2016 program Studi Teknik Komputer di AMIK BSI Jakarta. 